\title{
La educación ambiental como herramienta para conectar a las personas con su entorno inmediato
}

\author{
Oscar González Quiroz \\ oscar.gonzalez@ct.unanleon.edu.ni \\ Departamento de Biología \\ Universidad Nacional Autónoma de Nicaragua, León
}

Fabiola Areas Sevilla sevillaareas@gmail.com

Fundación Amigos del Río San Juan

\section{RESUMEN}

Frania López

franial_74@hotmail.es

Ministerio de Educación, León

Es imprescindible que la educación ambiental se convierta en una educación integral para la vida, que preserve una identidad ecológica, histórica y cultural. En este trabajo vamos a centrarnos en describir una experiencia de educación ambiental realizado en tres colegios de la zona costera del municipio de León (Nicaragua), desde el 2010 al 2018. El marco metodológico empleado está dividido en tres etapas; conocimientos generales del entorno, formación de promotores ambientales locales y facilitación de actividades enfocadas a la sostenibilidad del proceso. A través de la acción y reflexión, se destaca la importancia del ecosistema de manglar, la protección de tortugas marinas, la pesca responsable, turismo, cultura y aspectos socioambientales. Más de 883 estudiantes han participado directamente, fortaleciendo las capacidades locales con la formación de 20 promotores ambientales, con la responsabilidad de ejecutar acciones en sus comunidades. Los conocimientos adquiridos les han permitido ofertar servicios turísticos, como guías, utilizando los conocimientos adquiridos durante su formación como promotores ambientales. La mayoría continúan sus estudios a nivel universitarios en la Universidad, en distintas carreras. Los beneficios no solo han sido para los niños y jóvenes, también para aquellos que, como voluntarios, aportaron sus conocimientos con los estudiantes.

Palabras clave: educación ambiental; integral; conciencia; ecosistemas, sostenibilidad 


\title{
Environmental education as a tool to connect people with their immediate surroundings
}

\begin{abstract}
Nowadays, environmental education has become a comprehensive education for life to preserve an ecological, historical, and cultural identity. Through this study, an environment-linked education program was in place in three schools in the coastal area of León, Nicaragua, period 2010 - 2018. General knowledge of the environment, training of local environmental promoters, and reinforcement of process sustainability were the main themes for training. With action and reflection methodology, mangrove ecosystem, sea turtle's protection, responsible fishing and tourism, culture, and socio-environmental aspects, were included. More than 883 students involved strengthened their local capacities with direct training of 20 environmental promoters ready to develop actions in their communities. Their current knowledge allows them to offer tourism services from the experience acquired as environmentalism promoters. Nowadays, most of these large groups have continued their training at a university level, opting for different careers. This long-term environmentally educational program has not only benefited the scholars. It has also contributed to the community, particularly those members who, as volunteers, have steadily been part of this educational process contributing with their local and updated knowledge to children and youth at the school level.
\end{abstract}

Keywords: environmental education; integral; awareness; ecosystems, sustainability

Artículo recibido: 05 de Mayo 2021 Aceptado para publicación: 20 de Junio 2021 Correspondencia: oscar.gonzalez@ ct.unanleon.edu.ni Conflictos de Interés: Ninguna que declarar 


\section{INTRODUCCIÓN}

El medio ambiente es un sistema complejo y dinámico de interrelaciones ecológicas, socioeconómicas y culturales, que evoluciona a través del proceso histórico de la sociedad (Fernández Parrado, Guerrero Delgado, Pesante López, Batista Prieto \& Hernández Fernández, 2012). Las dimensiones socioculturales, políticas y económicas son fundamentales para entender las relaciones que la humanidad establece con su medio para utilizar mejor los recursos naturales (Gómez Sal, Belmontes \& Nicolau, 2003; Serrano, Rodríguez Morales \& Zúñigan Chaves, 2004).

El sistema de producción y consumo de los países desarrollados desde la Revolución Industrial parece insostenible. Los problemas ambientales son una consecuencia del modelo de desarrollo, de tal suerte que, como en todo sistema, las modificaciones introducidas en el sistema Tierra en su composición, atmosférica, en su población, la merma de los recursos, de la producción primaria, etc., están interactuando con el resto de las partes originando a su vez desajustes de consecuencias no bien conocidas, pero en todo caso impredecibles (Barea, 2009).

La identificación de los principales problemas ambientales de un país permite jerarquizar su atención, dirigiendo hacia ellos los principales esfuerzos de la gestión ambiental, dentro del universo de problemas existentes (Fernández Parrado et al., 2012):

- Degradación de los suelos (erosión, mal drenaje, salinidad, acidez, compactación, entre otros).

- Deterioro del saneamiento y las condiciones ambientales en asentamientos humanos.

- Contaminación de las aguas terrestres y marinas.

- Deforestación.

- Pérdida de diversidad biológica.

El compromiso para contrarrestar el impacto ciudadano común sobre el ambiente se ha fijado en la educación ambiental como esfuerzo internacional y multisectorial adoptado por los ministerios de educación nacional de la región latinoamericana (Medina Arboleda \& Páramo, 2014). Es imprescindible lograr que la Educación Ambiental se convierta en una educación integral para la vida, que preserve nuestra identidad ecológica, histórica y cultural. Para ello es preciso desarrollar valores que contribuyan a elevar la calidad de vida de la población y permitan avanzar hacia un desarrollo sustentable (Fernández Parrado et al., 2012). 


\section{ESTRATEGIAS METODOLÓGICAS}

Por lo anterior, el Departamento de Biología de la Universidad Nacional Autónoma de Nicaragua, León (UNAN-León), se dio a la tarea de crear un Programa de Educación Ambiental, dirigido al sector costero del municipio de León, Nicaragua. El objetivo principal fue promover la sensibilización y toma de conciencia de las y los estudiantes con respecto a su entorno ambiental, conociendo los problemas y las posibles alternativas de solución.

El Programa de Educación Ambiental nace en el 2010, dirigida inicialmente a estudiantes del colegio Andrés Castro (Las Peñitas), con la participación de 45 estudiantes de un aula multinivel ( $5^{\text {to }}$ y $6^{\text {to }}$ grado). En la ejecución del programa durante el primer año se involucraron estudiantes de la carrera de biología de la UNAN-León, Universidad de Alcalá, facilitadores de la Fundación Amigos de Río San Juan (FUNDAR), Ministerio del Ambiente y los Recursos Naturales (MARENA), Ministerio de Educación (MINED) y voluntarios nacionales. Por la comunidad fue notable la participación de jóvenes y padres de familia acompañando las diferentes actividades ejecutadas. Para el 2011 se continuó trabajando con el grupo de estudiantes de Las Peñitas y replicando la experiencia en Colegios de Poneloya y Salinas Grandes, aunque con menor sistematicidad que en Las Peñitas.

El programa de Educación Ambiental tiene cinco enfoques principales de acción:

1) Que los estudiantes reconozcan los problemas ambientales existentes en sus comunidades.

2) Estimular en los estudiantes el sentido crítico constructivo, que los lleve a elaborar propuestas de soluciones a los problemas ambientales del entorno.

3) Incentivar la protección de los recursos naturales por medio del conocimiento del ambiente en que viven.

4) Entender y aplicar los conceptos básicos de educación ambiental.

5) La formación de capacidades locales a través de promotores ambientales.

\section{Proceso de intervención}

Inicialmente se realizó una revisión de posibles temas a trabajar con los estudiantes, tomando en cuenta, aquellos relacionados al entorno local. Se destacaron temas sobre el ecosistema de manglar, la protección de tortugas marinas, las actividades de relacionada 
a la pesca y el turismo. A partir de estos ejes nos dimos a la tarea a elaborar el material para cada una de las sesiones planificadas en todo el año.

Se impartieron charlas en aulas de clase, durante siete meses, cada 15 días. Las presentaciones son muy visuales, con muchas imágenes y videos que permitan a los estudiantes un aprendizaje más dinámico y participativo. Los facilitadores del programa de educación ambiental son preparados para impartir las charlas. En el caso de la participación de los promotores ambientales locales, siempre están acompañados por la coordinación y voluntarios del Programa de Educación Ambiental. Se debe contar con los equipos básicos como una computadora portátil, proyector de imágenes y equipo de sonido.

De acuerdo a Novo (1995) es importante la tarea del educador ambiental para ayudar a las personas a pasar de nivel de opinión a la acción. Esta misma autora considera que se debe guiar al estudiante a comprender los problemas desde su realidad cotidiana, allí donde lo real les rodea. Se basa en el redescubrimiento de lo cotidiano, en la utilización del entorno inmediato como fuente de motivación para la educación y la acción ambiental. La teoría debe ser acompañada por práctica para los temas tratados, para garantizar la apropiación pertinente de información para el conocimiento y posicionamiento de los participantes (Raúdez Guzmán \& Silveira Kitzmann, 2006). Es así, que, se realizan recorridos de campo en la Reserva Natural Isla Juan Venado, aprovechando la existencia de un sendero que recorre el bosque seco tropical y el bosque de manglar. Los estudiantes pueden apreciar las diferencias entre el ecosistema de manglar y bosque seco (productividad y diversidad), así mismo, reconocen los bienes y servicios que obtienen las personas de la comunidad. Además, se incluyen actividades prácticas de avistamiento de aves, reforestación, liberación de tortugas marinas y evaluación del bosque de manglar. También, se realizan encuestas socioeconómicas por parte de los estudiantes para comprender su entorno social.

\section{RESULTADOS Y DISCUSIÓN}

Desde el 2010 al 2018 se viene trabajando con estudiantes de la escuela de Las Peñitas, Salinas Grandes y el Colegios de Poneloya, sumando 883 alumnos en total (Figura 1). En promedio se trabajó con 26 estudiantes por aula. El 100\% de los estudiantes visitaron la Reserva Natural. 
Figura 1: Número de estudiantes participantes directos en el programa de educación ambiental. Las flechas indican los estudiantes que quisieron continuar aprendiendo y

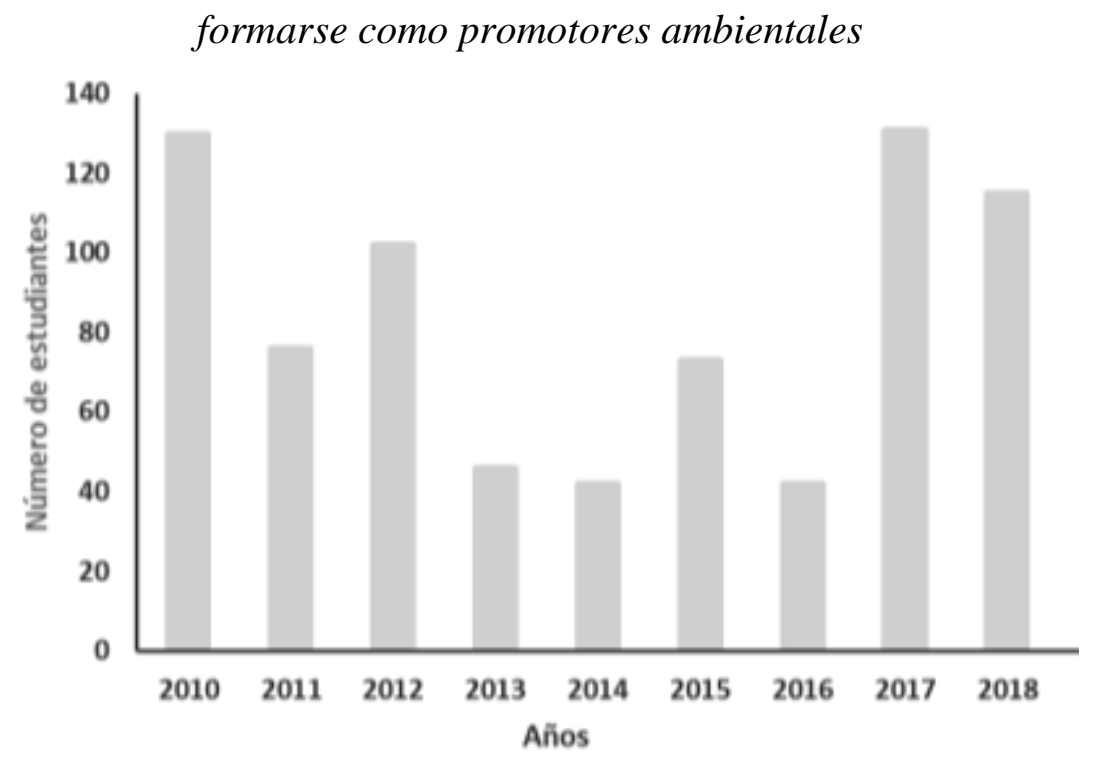

El marco metodológico empleado en el PEA está dividido en tres etapas; conocimientos generales del entorno, formación de promotores ambientales locales y facilitación de actividades enfocadas a la sostenibilidad del proceso:

Etapa I: consiste en la enseñanza de conceptos básicos sobre medio ambiente, sensibilización ambiental, conocimiento del entorno, educación, autoestima y organización. Se iniciaron los primeros recorridos de campo y prácticas que se realizaron en la Reserva Natural Isla Juan Venado. Aquellos niños interesados en continuar aprendiendo se les propusieron una formación continua que les sirviera para que posteriormente fueran parte del grupo de trabajo en la segunda etapa del programa. Este proceso lleva un año de formación en aula y un segundo año en prácticas de campo.

Etapa II: Continua el seguimiento de un grupo de jóvenes que tienen interés en participar en actividades de formación y prácticas de conservación en la comunidad, para obtener un reconocimiento como promotor ambiental de su comunidad. Es a partir de aquí que se realizan cursos libres de temas ambientales (ecosistemas, reptiles; tortugas marinas, aves, pesca, desechos y reciclaje), sociales (organización, género, maltrato a la mujer, autoestima) y cultural (teatro, danza y dibujo).

Es en esta etapa donde los jóvenes tienen la oportunidad de brindar charlas en las aulas a estudiantes de $5^{\text {to }}$ y $6^{\text {to }}$ grados. Este proceso lleva dos años. Se trata de que los alumnos comprendan y experimenten la realidad en sus más diversas dimensiones: sean de 
naturaleza tecnológica, económica, social o ambiental (Pérez Garcés, Victorino Ramírez, \& Quintero Soto, 2016).

Etapa III: es una etapa donde se trata de garantizar la sostenibilidad del proceso a través de los jóvenes promotores ambientales locales, los cuales sean capaces de organizarse, desarrollar las actividades de formación en las aulas de clase y la búsqueda de fondos económicos que permitan la continuidad del Programa de Educación Ambiental en su comunidad. En esta tercera etapa los promotores locales deberían estar finalizando sus estudios secundaria y dando el paso hacia la universidad o carreras técnicas. Todo el proceso para la formación de promotores ambientales se realiza en un periodo de cinco años continuos.

Para esta última etapa se implementación la transferencia de responsabilidad desde la coordinación del PEA a los promotores locales. De hecho, durante el 2015 se graduaron 20 promotores locales de la comunidad de Las Peñitas, los cuales tienen la responsabilidad de dar continuidad a las acciones del PEA en la comunidad. Cabe destacar que el PEA tiene un carácter participativo y colaborativo, logrando la participación de investigadores, docentes, voluntarios, estudiantes de pregrado de diferentes disciplinas, líderes locales y padres de familia.

\section{Situación final}

Se ha creado capacidad local, donde los promotores ambientales, formados en el marco del Programa de Educación Ambiental tienen el compromiso de darle continuidad a las actividades teóricas (charlas) y prácticas (recorridos de campo). Se trabajan las presentaciones nuevas con los promotores y luego se tienen reuniones especificas con los jóvenes dependiendo del tema a tratar. Cada promotor escoge un tema, el cual estudia a profundidad para presentar a sus compañeros.

La educación ambiental debe ser vista como un proceso a mediano y largo plazo que permita ver cambios sociales y ambientales en los pobladores. Bajo esta premisa, en el 2019 los promotores ambientales tienen la responsabilidad de ejecutar las actividades en Las Peñitas y Poneloya, acompañando la teoría y la práctica, así mismo en la consecución de fondos y creación de alianzas locales. Se mantiene la participación de investigadores, docentes, voluntarios, estudiantes de pregrado de diferentes disciplinas, así como el involucramiento de los padres de familia. 
Es importante destacar que ninguno de los promotores ambientales tiene alguna actividad relacionada con la explotación de los recursos naturales. De hecho, ocho de ellos ofertan servicios turísticos, como guías, utilizando los conocimientos adquiridos durante su formación como promotores ambientales. Siete continúan sus estudios a nivel universitarios en la UNAN-León, en distintas carreras. Estos han sido apoyados a través de becas por parte de la universidad.

Los beneficios no solo han sido para los niños y jóvenes, también para aquellos que, como voluntarios, aportaron sus conocimientos con los estudiantes, han logrado adquirir experiencias positivas que les han valido para incluir la referencia de su participación en el PEA en su curriculum vitae.

Los niños y jóvenes de las comunidades aledañas a la Reserva Natural Isla Juan Venado son los llamados a hace diferencia en el futuro. De la formación cognitiva y no cognitiva de los niños y jóvenes dependerá alcanzar los cambios que permitan disminuir el deterioro ambiental (Novo, 1995). Esto es tangible en los niños y jóvenes de las comunidades aledañas al área protegida Isla Juan Venado.

La experiencia en el PEA nos indica que el aprendizaje por la acción juega un papel importante para actuar en forma práctica en relaciones complejas. Según Pérez Garcés et al., (2016) para el contexto, las etapas de reflexión, planificación, ejecución, análisis y evaluación son pasos fundamentales que son tematizados y analizados en el proceso de aprendizaje por la acción: reflexionando y haciendo, el alumno o aprendiz elabora soluciones a problemas que se manifiestan en su contexto, sean éstos de índole técnica, formativa o social.

\section{CONSIDERACIONES FINALES}

La educación ambiental debe ser un proceso permanente y dinámico, que vincule la teoría con la práctica, como una forma de contribuir a la cultura ambiental de las comunidades. Las alianzas entre distintos actores locales fortalecen los procesos de mediano y largo plazo.

Es necesario la creación de capacidades locales para garantizar la sostenibilidad de los procesos, donde se busca alcanzar un cambio positivo en la actitud y aptitud hacia el ambiente. 
El desarrollo de programas de educación ambiental debe partir de compromisos y responsabilidades como ciudadanos preocupados por el presente y futuro de la humanidad.

\section{LISTA DE REFERENCIAS}

Espejel Rodriguez, A., \& Flores Hernández, A. (2012). Educación ambiental escolar y comunitaria en el nivel medio superior Puebla-Tlaxcala, México. Revista Mexicana de Investigación Educativa, 17(55), 1173-1199.

Fernández Parrado, C., Guerrero Delgado, D., Pesante López, E., Batista Prieto, F. F., \& Hernández Fernández, D. (2012). La educación ambiental, una necesidad de estos tiempos. Revista Digital, 17(175), 1-4.

Gómez Sal, A., Belmontes, J.-A., \& Nicolau, J.-M. (2003). Assessing landscape values: a proposal for a multidimensional conceptual model. Ecological Modelling, 168(3), 319-341. https://doi.org/10.1016/S0304-3800(03)00144-3

Jiménez Tello, M. J., Yebra-Rodríguez, Á., \& Guerrero, F. (2015). Las bases de la educación ambiental. Iniciación a La Investigación, 6(1), 1-11.

Kudryavtsev, A., Stedman, R. C., \& Krasny, M. E. (2012). Sense of place in environmental education. Environmental Education Research, 18(2), 229-250. https://doi.org/10.1080/13504622.2011.609615

Martínez Castillo, R. (2010). La importancia de la educación ambiental ante la problemática actual. Revista Electrónica Educare, XIV(1), 97-111.

Medina Arboleda, I. F., \& Páramo, P. (2014). La investigación en educación ambiental en América Latina : un análisis bibliométrico. Revista Colombiana de Educación, $66,55-72$.

Novo, M. (1995). La educación ambiental: bases éticas, conceptuales y metodológicas.

Novo, M. (2009). La educación ambiental, una genuina educación para el desarrollo sostenible. Revista de Educación, No Extraor, 195-217.

Pepito Escudero, C., Rejas Ayugay, J. G., \& González Quiroz, O. (2017). Aplicación de los sistemas de información geográficos y teledetección en el estudio del arraigo del patrimonio cultural y natural, y su influencia en los movimientos migratorios, en el corredor mesoamericano. Caso de estudio: León, Nicaragua.

Pérez Garcés, R., Victorino Ramírez, L., \& Quintero Soto, M. L. (2016). Educación ambiental y sociedad. 
Raúdez Guzmán, J. E., \& Silveira Kitzmann, D. L. (2006). El gestor ambiental como generador del conocimiento ambiental : experiencia en Nicaragua . In Congreso Iberoamericano de Ciencias, Tecnología, Innovación y Educación (pp. 2-11).

Romero Barea, G. (2009). Educar en valores: respeto al medioambiente. Innovación y Experiencias Educativas, 24, 1-9.

Serrano, E. G., Rodríguez Morales, M., \& Zúñigan Chaves, E. M. (2004). Educación Ambiental en Costa Rica: tendencias evolutivas, perspectivas y desafíos *. Revista Biocenosis, 18(1-2), 2-25. 